\title{
Dilated Cardiomyopathy in a Child with COVID-19
}

\author{
Rashmi Kishore $^{1}$ (D) - Avinash Choudekar ${ }^{2} \cdot$ Ashit Bhusan Xess $^{2} \cdot$ Lalit Dar $^{2} \cdot$ Rahul Kumar Anand $^{3} \cdot$ Anita Saxena $^{4}$. \\ S. K. Kabra ${ }^{1}$
}

Received: 1 September 2020 / Accepted: 5 October 2020 / Published online: 10 October 2020

(C) Dr. K C Chaudhuri Foundation 2020

To the Editor: The coronavirus disease (COVID-19) is though primarily a respiratory tract infection, various extrapulmonary complications have also been reported. We hereby report dilated cardiomyopathy (DCM) in a one-year-old premorbidly healthy boy.

A one-year-old boy presented with low-grade fever for two days, followed by generalized swelling all over body and tachypnea for one week. Past and family history were not contributory. He was admitted in an outside hospital for five days with diagnosis of congestive cardiac failure (CCF). Investigations done there revealed cardiomegaly on chest $\mathrm{X}$ ray (CXR), iron deficiency anemia $(\mathrm{Hb} 6.3 \mathrm{~g} / \mathrm{dl}$, microcytic hypochromic smear, ferritin $3.4 \mu \mathrm{g} / \mathrm{L}$ ), deranged liver function tests (total bilirubin $1.55 \mathrm{mg} / \mathrm{dl}$, indirect $1.13 \mathrm{mg} / \mathrm{dl}$, AST $245 \mathrm{U} / \mathrm{L}$, ALT $280 \mathrm{U} / \mathrm{L}$, ALP $278 \mathrm{U} / \mathrm{L}$ ) and normal CRP $(0.7 \mathrm{mg} / \mathrm{L})$. Rest of the investigations were normal. Echo revealed dilated ventricles with global hypokinesia with left ventricular ejection fraction of $12 \%$ and normal coronaries. Child was managed symptomatically and referred for specialized care.

At presentation to our hospital he had tachycardia, tachypnea (heart rate $170 / \mathrm{min}$, respiratory rate $36 / \mathrm{min}$ ) and $\mathrm{SaO}_{2}$ of $97 \%$ in room air. He was still in CCF with basal crepitations and hepatomegaly of $4 \mathrm{~cm}$. Investigations in Emergency department (ED) showed cardiomegaly on

Rashmi Kishore

rashmi.k186@gmail.com

1 Department of Pediatrics, All India Institute of Medical Sciences, New Delhi 110029, India

2 Department of Microbiology, All India Institute of Medical Sciences, New Delhi, India

3 Department of Anesthesiology, All India Institute of Medical Sciences, New Delhi, India

4 Department of Cardiology, All India Institute of Medical Sciences, New Delhi, India
CXR, Hb 8.7 g/dL, TLC 12,200 with 50\% neutrophils, $43 \%$ lymphocytes and platelet count of $74,000 / \mathrm{mm}^{3}$. The electrocardiogram (ECG) did not show any abnormality. In view of severe left ventricular dysfunction and CCF, furosemide and dobutamine infusion was started. His rRTPCR for the SAR-CoV-2 ORF $1 \mathrm{ab}$ gene done by a commercial kit (BGI Genomics Co. Ltd., China) on nasopharyngeal swab was positive. He was admitted in isolation ward while inotropes and diuretics were continued. However, his CCF persisted and inotropes were hiked. He suffered a sudden cardiac arrest $33 \mathrm{~h}$ after admission from which he could not be revived.

Viral infection is a known secondary cause of DCM [1]. CCF has been reported in 23\% of COVID-19 patients [2]. Arentz et al. reported cardiomyopathy in $33 \%$ of critically sick COVID-19 patients [3]. Viral myocarditis may also present acutely with CCF and ventricular dilation but has a milder course while fulminant myocarditis has normal cardiac chamber sizes [4]. Our patient had normal ECG and inflammatory markers. He had recent onset cardiomyopathy, as he was premorbidly normal, did not have pneumonia, metabolic abnormality, or fluid overload, ruling out secondary myocardial dysfunction or stress cardiomyopathy. DCM was possibly due to coronavirus infection though the etiological role of the virus could not be proved.

Acknowledgments Director General, Indian Council of Medical Research, for providing funding for support of diagnostics.

\section{Compliance with Ethical Standards}

Conflict of Interest None.

\section{References}

1. Jefferies JL, Towbin JA. Dilated cardiomyopathy. Lancet. 2010;375: $752-62$. 
2. Zhou F, Yu T, Du R, et al. Clinical course and risk factors for mortality of adult inpatients with COVID-19 in Wuhan, China: a retrospective cohort study. Lancet. 2020;395:1054-62.

3. Arentz M, Yim E, Klaff L, et al. Characteristics and outcomes of 21 critically ill patients with COVID-19 in Washington state. JAMA. 2020;323:1612-4.
4. Kindermann I, Barth C, Mahfoud F, et al. Update on myocarditis. J Am Coll Cardiol. 2012;59:779-92.

Publisher's Note Springer Nature remains neutral with regard to jurisdictional claims in published maps and institutional affiliations. 